\title{
Curriculum Orientations and Educational Philosophies of High School Arabic Teachers
}

\author{
Abeer Saleh Alsalem ${ }^{1}$ \\ ${ }^{1}$ College of Social Sciences, Imam Muhammad ibn Saud Islamic University, Kingdom of Saudi Arabia \\ Correspondence: Abeer Saleh Alsalem, College of Social Sciences, Imam Muhammad ibn Saud Islamic \\ University, Kingdom of Saudi Arabia. E-mail: absalsalem@imamu.edu.sa
}

Received: November 27, 2017

Accepted: January 5, 2018

Online Published: March 28, 2018

doi:10.5539/ies.v11n4p92

URL: https://doi.org/10.5539/ies.v11n4p92

\begin{abstract}
This study aims to investigate the curriculum orientations of High school Arabic teacher in Riyadh city and to examine the relationship between curriculum orientation and their educational philosophies. The quantitative method (descriptive study) was adopted in this questionnaire survey-based study. Mean and standard deviation for the overall of the curriculum orientations and for each orientation were obtained and Pearson correlation coefficient was also used to examine the relationship between the curriculum orientations and their educational philosophies. The results show that Arabic teachers of High school considered all five curriculum orientations with the self-actualization/ Humanism ranked the highest orientation and the cognitive process ranked the lowest orientation. The current study also indicates that there is a positive relationship at the level of $(0.05)$ between the curriculum orientations and the educational philosophies of the Arabic language teachers in High school.
\end{abstract}

Keywords: curriculum orientation, educational philosophy, Arabic teaches of high school

\section{Introduction}

Curriculum orientation is defined as teachers' belief about the education goal and the curriculum components such as objectives, content, teaching, learning, activities, and assessment methods (Cheung \& Ng, 2000). Eisner and Vallance (1947) propose five curriculum orientations: academic rationalism, cognitive process, social reconstruction, self-actualization and technology. Each orientation has specific beliefs about curriculum design and curriculum elements (Cheung \& Wong, 2002). Academic rationalism stresses that intellectual process and content help students act like historian or scientific. The role of teacher is to assist students in mastering of the concepts, content and the main ideas of the academic discipline (Tanriverdi \& Apak, 2014). Unlike the academic rationalism, cognitive process orientation focuses on learning process than content; therefore, the role of teacher is to facilitate the learning process and create environment that help students practice solve-problem skills, ask questions and think critically.

The third orientation is Self-Actualization (Humanistic) stresses the students' needs and interests, so the role of teacher is to provide students with opportunities and experiences that allow them to grow and to serve their personal development (Tanriverdi \& Apak, 2014). Otherwise, the curriculum of social reconstruction orientation centers to communities' problems. Therefore, the aim of curriculum is to help students think about their communities' issues and try to solve them and make decisions, and the role of teacher is to create safe and open environment that encourage students to ask questions and think critically and reflectively. Technology orientation is the fifth curriculum orientation which focuses on planning the curriculum systematically so the role of teacher is to set the learning objective and achieve them (Eisner \& Vallance, 1947).

Teachers adopt the curriculum orientations based on their educational philosophy (s) and their orientations of curriculum are influenced by their philosophies (Tanriverdi \& Apak, 2014). In the literature of education, there are four main educational philosophes which related to the curriculum orientation. The first philosophy is Perennialism that emphasizes subject matter, content, and knowledge, including the so-called "humanities," the common culture of Western civilization (grammar, reading, rhetoric, logic, mathematics, and great literature). Hutchins called these the "permanent studies" (Hlebowitsh, 2005, p. 59). Proponents of perennialism care about keeping and passing on their culture from one generation to the next. Therefore, the role of the student is to receive knowledge from the teacher and the role of the teacher is to teach the student basic knowledge and the skills necessary to gaining an understanding of the content. These skills will enable students eventually think of their 
way through the subject matter" (Hlebowitsh, 2005, p. 60).

The second philosophy is Progressivism which is embodied in Dewey's theory which places more emphasis on the learners than on subject matter. Progressivist philosophy cares about the reconstruction of experience, meaning that it is helpful for learners to learn from their experience to avoid repeating their mistakes. Therefore, they will be able to make wiser decisions in the future. In addition, such reconstruction will allow learners to create new knowledge based on their prior knowledge and experiences (Null, 2011). A progressivist environment encourages students to ask good questions, especially those starting with "why." This will assist them in developing the ability to think more critically, solve problems, and to enjoy collaboration and engagement with others. The third philosophy is social efficiency that focuses on society needs and it emphasizes on designing the educational objectives. The proponents of this ideology such as Bobbitt, 1913 and Tyler 1949 believed that the educational objectives help curriculum makers design the other components of curriculum such as the learner experience, content, activities, and the methods of assessment. With social efficiency philosophy, the learner work in school that provides their energy for educational product, and the role of the teacher is to manage the conditions of the learning (Schiro, 2013).

The fourth philosophy is Social Reconstructionism that places emphasis on addressing social questions to create a better society. In addition, it should be devoted to the promotion of social welfare through education (Counts, 1978, p. 5). It believes that ethics and intellect cannot be separated (Null, 2011, p.112). The role of the school is to prepare people to create a new social order. In addition, educators should focus on a curriculum that highlights social reform as the aim of education, and focuses on student experience and on taking social action to resolve real problems such as hunger, international terrorism, inflation, and inequality. Teachers should create an environment that helps students understand social problems and assist learners in finding proper solutions to them (Hlebowitsh, 2005, pp. 77-78).

Proponents of curriculum design, such as Tyler and Dewey, assert that adopting an appropriate orientation and philosophy to develop and design teaching and curriculum is very important. Doing so may help teachers find solutions to some of their problems. According to Tyler (1949), the role of orientation and philosophy in curriculum design is to emphasize teacher goals within the classroom. Moreover, Ornstein and Hunkins (2009) agree that orientation and philosophy provide a framework for curriculum designers such as teachers that helps them determine the school's goals that they should aim towards, the most worthwhile subject matter they should teach, how students will learn subject matter, strategies the teachers will use, proper experiences and activities they should organize, and how to ensure that educational objectives are achieved. A philosophy is a guide for implementing teaching processes and actions. Therefore, "all curriculum texts should incorporate theory and be systematic in approach, and establish worthwhile practices" (Ornstein \& Hunkins, 2009, p. 19).

Even though there is an increased interest in curriculum orientations and educational philosophy, it is surprising that few studies have been conducted on this topic (Salleh, Hamdan, Yahya, \& Jantan, 2015; Tanriverdi \& Apak, 2014). No one of them aimed to investigate the relationships between the curriculum orientations and educational philosophies, and no one of them investigated Arabic high school teachers. In this research study, beliefs of High school Arabic teachers of curriculum orientations in Riyadh and to examine the relationship between curriculum orientations and their educational philosophies were investigated.

\section{Research Questions}

The current study tries to answer the two following research questions:

- What are the curriculum orientations of High school's Arabic teacher in Riyadh?

- What is the relationship between curriculum orientation of High school's Arabic teacher and their educational philosophies?

\section{Methodology}

This study is quantitative research (descriptive study) using questionnaire survey to investigate the curriculum orientation of 200 female Arabic teachers of High school in Riyadh and to examine the relationship between curriculum orientation and their educational philosophies. The researcher used a questionnaire that was divided into two sections: The first section was about curriculum orientations that was translated and adopted based on Cheung and Wong's (2002) Curriculum Orientation Inventory (COI) that assesses the five curriculum orientations: academic rationalism, cognitive process, social reconstruction, humanistic, and technological. There were 30 items and all items were translated into Arabic language.

The second section is about educational philosophies. The items of this section were 20 items that were chosen from the literature of educational philosophies. The validity of the survey was established using content-related 
validity through experts in curriculum and instruction for recommendations on wording and relevance of items as the content validity of this instrument was an important indicator of the validity of the results. To establish the instrument reliability, internal consistency was verified through using alpha Cronbach. The overall alpha Cronbach coefficient of 0.75 , curriculum orientations (0.75): academic rationalism orientation (0.77), cognitive process orientation (0.78), social reconstruction orientation (0.78), self-actualization orientation ( 0.78$)$, and technology orientation (0.79). Educational philosophies (0.75): Perennialism philosophy (0.80), progressive philosophy (0.79), social efficiency philosophy (0.83), and social reconstruction philosophy (0.82).

The mean and standard deviation for each of the subscales of curriculum orientation were used. The computed Pearson (r) correlation coefficient was obtained to determine whether there is a significant relationship between the curriculum orientations and educational philosophies.

\section{Findings}

To answer the first research question, the researcher used mean, standard deviation, and the percentage for the overall of the curriculum orientations and for each orientation as Table 1 shows.

Table 1. Mean and standard deviation for the overall of the curriculum orientations and for each orientation

\begin{tabular}{lcc}
\hline Curriculum Orientations & M & SD \\
\hline Self-actualization/Humanism & 4.26 & 1.09 \\
Academic Rationalism & 4.16 & 1.66 \\
Technology & 4.15 & 1.56 \\
Social Reconstruction & 3.94 & 1.51 \\
Cognitive Process & 3.93 & 1.30 \\
Overall of Curriculum Orientations & 4.08 & 2.15 \\
\hline
\end{tabular}

Table 1 demonstrates that the self-actualization/ Humanism ranked the highest orientation that Arabic teachers of High school adopt in their curriculum. Academic Rationalism was the second orientation. Technology orientation was the third orientation. Social reconstruction was the fourth orientation. The cognitive process was the last orientations that they used in their teaching and in designing curricula.

To answer the second question, Pearson correlation coefficient was used to examine the relationship between the curriculum orientations and the educational philosophies for the study's sample as shown in Table 2.

Table 2. Correlation coefficient between the curriculum orientations and the educational philosophies

\begin{tabular}{|c|c|c|c|c|c|c|c|c|c|c|c|}
\hline $\begin{array}{c}\text { Variab } \\
\text { les }\end{array}$ & $\begin{array}{c}\text { AR } \\
\text { Academic } \\
\text { Rationalism }\end{array}$ & $\begin{array}{c}\text { CP } \\
\text { ognitive } \\
\text { Process }\end{array}$ & $\begin{array}{c}\text { SR } \\
\text { Social } \\
\text { Reconstruction }\end{array}$ & $\begin{array}{c}\mathrm{H} \\
\text { Human } \\
\text { ism }\end{array}$ & $\begin{array}{c}\mathrm{T} \\
\text { Technol } \\
\text { ogy }\end{array}$ & $\begin{array}{c}\text { CO } \\
\text { Curriculum } \\
\text { Orientations }\end{array}$ & $\begin{array}{c}\text { P1 } \\
\text { Perennial } \\
\text { ism }\end{array}$ & $\begin{array}{c}\text { P2 } \\
\text { Progressi } \\
\text { vism }\end{array}$ & $\begin{array}{c}\text { SE } \\
\text { Social } \\
\text { Efficiency }\end{array}$ & $\begin{array}{c}\text { SR } \\
\text { Social } \\
\text { Reconstruction }\end{array}$ & $\begin{array}{c}\text { EP } \\
\text { Educational } \\
\text { Philosophies }\end{array}$ \\
\hline AR & 1 & $.458^{* *}$ & $.355^{* *}$ & $.333 * *$ & $.289^{* *}$ & $.643 * *$ & $.357 * *$ & $.223 *$ & $.346^{* *}$ & $.299 * *$ & $.421^{* *}$ \\
\hline $\mathrm{CP}$ & $.458 * *$ & 1 & $.557 * *$ & $.437 * *$ & $.547 * *$ & $.778^{* *}$ & $.290^{* *}$ & $.553^{* *}$ & $.541^{* *}$ & $.451^{* *}$ & $.606^{* *}$ \\
\hline SR & $.355^{* *}$ & $.557^{* *}$ & 1 & $.641^{* *}$ & $.404 * *$ & $.749^{* *}$ & $.234 *$ & $.455^{* *}$ & $.407 * *$ & $.400^{* *}$ & $.429^{* *}$ \\
\hline $\mathrm{H}$ & $.333 * *$ & $.437^{* *}$ & $.641^{* *}$ & 1 & $.583 * *$ & $.744^{* *}$ & 0.131 & $.609^{* *}$ & $.474 * *$ & $.542 * *$ & $.518^{* *}$ \\
\hline $\mathrm{T}$ & $.289^{* *}$ & $.547^{* *}$ & $.404 * *$ & $.583 * *$ & 1 & $.759 * *$ & $.289^{* *}$ & $.595^{* *}$ & $.584^{* *}$ & $.506^{* *}$ & $.620^{* *}$ \\
\hline $\mathrm{CO}$ & $.643 * *$ & $.778^{* *}$ & $.749 * *$ & $.744 * *$ & $.759 * *$ & 1 & $.290^{* *}$ & $.602 * *$ & $.621^{* *}$ & $.562 * *$ & $.644 * *$ \\
\hline P1 & $.357 * *$ & $.290^{* *}$ & $.234 *$ & 0.131 & $.289 * *$ & $.290^{* *}$ & 1 & 0.13 & $.284^{*}$ & 0.203 & $.608^{* *}$ \\
\hline P2 & $.223 *$ & $.553^{* *}$ & $.455^{* *}$ & $.609 * *$ & $.595^{* *}$ & $.602 * *$ & 0.13 & 1 & $.602 * *$ & $.646^{* *}$ & $.720^{* *}$ \\
\hline SE & $.346^{* *}$ & $.541^{* *}$ & $.407 * *$ & $.474^{* *}$ & $.584 * *$ & $.621 * *$ & $.284 *$ & $.602^{* *}$ & 1 & $.645^{* *}$ & $.769^{* *}$ \\
\hline SR & $.299 * *$ & $.451^{* *}$ & $.400^{* *}$ & $.542 * *$ & $.506^{* *}$ & $.562 * *$ & 0.203 & $.646^{* *}$ & $.645^{* *}$ & 1 & $.766^{* *}$ \\
\hline EP & $.421 * *$ & $.606^{* *}$ & $.429^{* *}$ & $.518^{* *}$ & $.620^{* *}$ & $.644 * *$ & $.608^{* *}$ & $.720 * *$ & $.769 * *$ & $.766 * *$ & 1 \\
\hline
\end{tabular}

Table 2 indicates that there is a positive relationship at the level of (0.05) or less between the curriculum orientations and the educational philosophies of the Arabic language teachers in High school. This means that the 
teachers' curriculum orientations are affected by their philosophies of education.

\section{Conclusion and Discussion}

The education in high school focuses on two educational philosophies: progressivism and social reconstruction which is related to cognitive process, social reconstruction, and self-actualization orientations. In this study all orientations were considered, the self-actualization/ Humanism was the highest orientation, Academic Rationalism was the second orientation. Technology orientation was the third orientation. Social reconstruction was the fourth orientation. The cognitive process was the lowest orientation. However, Arabic teachers of high school adopt Academic Rationalism and Technology orientation more than self-actualization/ Humanism, social reconstruction, and cognitive process orientations which means that the Arabic teachers of high school design their curricula based on traditional educational philosophy (Perennialism) that emphasizes content and knowledge more than students and focuses on remembering skills more than critical thinking. This study agrees with the results of Tanriverdi and Apak (2014) in terms of humanistic orientation but differs from this study s in terms of social reconstruction which ranks the lowest in this study but ranks fourth in the current study. This study also does agree with the finding of Salleh et al. (2015) in terms of cognitive process orientation ranks the lowest orientation but differs from this study in terms of technology orientation which ranks the highest in their study but ranks third in this study.

The current study also demonstrates that there is a positive relationship at the level of (0.05) between the curriculum orientations and the educational philosophies of the Arabic language teachers in High school which means that when teachers emphasize adopting academic rationalism orientation, they design their curricula based on the principles of perennialism philosophy in terms of the role of students, the role of teachers, knowledge, assessment and the rest of curriculum components. On the other hand, when teachers adopt cognitive process orientation, they design their teaching and curriculum based on progressive philosophy.

\section{References}

Cheung, D., \& Ng, P. H. (2000). Science teachers' beliefs about curriculum design. Research in Science Education, 30, 357-375. https://doi.org/10.1007/BF02461556

Cheung, D., \& Wong, H. W. (2002). Measuring teacher beliefs about alternative curriculum designs. The Curriculum Journal, 13(2), 225-248. https://doi.org/10.1080/09585170210136868

Counts, G. S. (1978). Dare the school build a new social order? Carbondale: Southern Illinois University.

Eisner, E. W., \& Vallance, E. (1974). Conflicting conceptions of curriculum. Berkeley, CA: McCutchan.

Hlebowitsh, P. (2005). Designing the school's curriculum. Boston, MA: Allyn\&Bacon.

Null, W. (2011). Curriculum from theory to practice. Plymouth PL67PY, United Kingdom.

Ornstein, A., \& Hunkins, F. (2009). Curriculum: foundations, principles, and issues. Boson, MA.

Salleh, H., Hamdan, A., Yahya, F., \& Jantan, H. (2015). Curriculum Orientation of Lecturers in Teacher Training College in Malaysia. Journal of Education and Practice, 2, 70-76.

Schiro, S. (2013). Curriculum theory: Conflicting vision and enduring concerns. London, Kingdom: SAGE.

Tannerdi, B., \& Apak, O. (2014). Pre-service Teachers' Beliefs about Curriculum Orientations. Social and Behavioral Sciences, 116, 842-848.

Tyler, R. (1949). Basic principles of curriculum and instruction. Chicago, IL: University of Chicago Press.

\section{Copyrights}

Copyright for this article is retained by the author(s), with first publication rights granted to the journal.

This is an open-access article distributed under the terms and conditions of the Creative Commons Attribution license (http://creativecommons.org/licenses/by/4.0/). 